\title{
EDUCAÇÃO POPULAR EM SAÚDE NO CUIDADO À CRIANÇA DESNUTRIDA $^{1}$ POPULAR HEALTH EDUCATION IN CARING FOR THE UNDERNOURISHED CHILD EDUCACIÓN POPULAR EN SALUD EN EL CUIDADO AL NIÑO DESNUTRIDO
}

\author{
Mirna Albuquerque Frota², Conceição de Maria de Albuquerque 3 , Andrea Gomes Linard ${ }^{4}$
}

${ }^{1}$ Texto elaborado a partir da dissertação de mestrado "Educação popular em saúde no cuidado da desnutrição infantil", defendida no Mestrado em Educação em Saúde da Universidade de Fortaleza (UNIFOR), em 2005.

2 Enfermeira. Doutora em Enfermagem. Professora Adjunto do Curso de Graduação em Enfermagem e do Mestrado em Saúde Coletiva da UNIFOR.

${ }^{3}$ Enfermeira do Núcleo de Atenção Médica Integrada (NAMI) da UNIFOR. Mestre em Educação em Saúde pela UNIFOR.

${ }^{4}$ Enfermeira. Doutora em Enfermagem. Professora Adjunto da UNIFOR. Líder do Grupo de Pesquisa Saúde Coletiva da UNIFOR.

PALAVRAS-CHAVE: Transtorno da nutrição infantil. Educação em saúde. Cuidado da criança.

KEYWORDS: Child nutrition disorders. Health education. Child care.

PALABRAS CLAVE: Trastornos de la nutrición del niño. Educación en salud. Cuidado del niño.
RESUMO: Objetivou-se identificar a percepção dos pais acerca das oficinas de educação e saúde e propor ações de educação popular em saúde na assistência à criança desnutrida. Trata-se de uma pesquisa-ação desenvolvida no Núcleo de Atenção Médica Integrada, vinculado à Universidade de Fortaleza, no estado do Ceará. Participaram oito mães e um pai, cujas idades variavam de 20 a 48 anos, no período de março a agosto de 2005. Na coleta de dados utilizou-se entrevistas semi-estruturadas e oficinas educativas. Após a organização dos resultados, identificou-se a categoria "consciência do cuidado". O método despertou nova consciência no cuidado com o filho desnutrido na cultura da comunidade. Recomendam-se intervenções de educação popular em saúde para grupos culturalmente distintos, considerando as propostas, e incentivando na formulação de opções os desafios da saúde coletiva, buscando mudanças na constituição de práticas comprometidas com o rompimento das barreiras sociais, econômicas e políticas.

ABSTRACT: This study aimed to identify the parents' perceptions about the undernourished child and to propose popular health education actions for the undernourished child assistance in the city of Fortaleza, Ceará, Brazil. It deals with an active research developed at the Nucleus of Integrated Medical Attention, part of the University of Fortaleza. Eight mothers and a father participated in the study, whose ages varied from 20 to 48 years old during the period of March to August, 2005. The data was collected using semi-structured interviews and educational workshops. After organizing of the results, the following category was identified: care conscience. The method calls attention for a new conscience in the care of the undernourished child in the community culture. We recommend interventions of popular health education for culturally distinct groups, considering the proposals, and stimulating in the construction of options for challenges of collective health, seeking changes in the constitution of practices committed to the disruption of social, economic, and political barriers.

RESUMEN: El objetivo de este estudio fue identificar la percepción de los padres acerca del hijo desnutrido, así como proponer acciones de educación popular para la salud en la asistencia al niño desnutrido en la ciudad de Fortaleza - Ceará. Se trata de una investigación-acción desarrollada en el Núcleo de Atención Médica Integrada, vinculado a la Universidad de Fortaleza. En la investigación participaron ocho madres y un padre, cuyas edades variaban de 20 a 48 años, en el período de marzo a agosto de 2005. La recolección de los datos se realizó mediante entrevistas parcialmente estructuradas y actividades educativas. Después de la organización de los resultados, fue identificada la categoría: conciencia del cuidado. El método despertó una nueva conciencia en el cuidado del hijo desnutrido en la cultura de la comunidad. A partir de este estudio, se recomiendan intervenciones de educación popular en salud para grupos culturalmente distintos, considerando propuestas e incentivando la formulación de opciones a los desafíos de la salud colectiva, buscando cambios en la constitución de prácticas comprometidas con la ruptura de barreras sociales, económicas y políticas.
Endereço: Mirna Albuquerque Frota

R. Manoel Jacaré, 150, Ap.1401

60.175-110 - Meireles, Fortaleza, CE.

E-mail: mirnafrota@unifor.br
Artigo original: Pesquisa

Recebido em: 16/11/2006.

Aprovação final: 18/04/2007. 


\section{INTRODUÇÃO}

A desnutrição, no cenário da atenção primária, deve ser percebida como um problema social e não puramente como de saúde pública, visto que, em decorrência de sua natureza multifatorial, é necessário transcender do domínio dos profissionais de saúde para o planejamento técnico e burocrático. Sejam estas resultantes de intervenção governamental ou de forças externas, essas transformações têm afetado uma grande parte da população mundial repercutindo em alterações significativas nas relações familiares. A repercussão desta patologia pode gerar danos graves, comprometendo o crescimento e o desenvolvimento da população infantil. $\mathrm{O}$ fato de a desnutrição ser, ainda, um dos episódios que acometem as crianças nos ambulatórios de pediatria do Núcleo de Atenção Médica Integrada (NAMI), contribuiu para chamar a atenção das pesquisadoras no tocante à problemática.

Assistindo a uma comunidade carente, que se localiza em uma área adstrita ao campus da Universidade de Fortaleza (UNIFOR), acompanhou-se de forma direta e atuante o decorrer das atividades de enfermagem relacionadas à saúde da criança em atenção primária, por meio da puericultura, imunização, consulta de enfermagem, visitas domiciliares, dentre outras. É válido ressaltar que, no período de atuação no serviço do Sistema Único de Saúde (SUS), as mudanças ocorridas no âmbito social, político e econômico não foram significativas se comparadas ao tempo de prática, assemelhando-se, deste modo, à própria política de saúde vigente no país, a qual, apesar de muitas modificações em programas teóricos, valoriza a doença (patologia) e não o doente (paciente/cliente), alimentando a continuidade do modelo biomédico, repercutindo na qualidade de vida das populações fragilizadas e no aumento da pobreza.

A pobreza tem uma definição superficialmente simples, pois, em relação à riqueza, está ligada a uma condição na qual um indivíduo (ou uma família) não tem acesso à qualidade de vida inserida nos padrões socialmente estabelecidos em certo momento histórico. ${ }^{1}$

Durante as atividades assistenciais, percebeu-se o crescimento do número de crianças acometidas de distúrbios nutricionais que, muitas vezes, passavam despercebidos nas consultas de ambulatórios. E quanto mais se questionavam os responsáveis pelo cuidado da criança mais propostas eram obtidas, despertando o sentimento de que, inúmeras vezes, ocorria a necessidade da participação da família. Constatou-se que o distanciamento entre o saber popular da família e o saber técnico dos profissionais de saúde provocava barreiras para a educação em saúde. Uma dessas barreiras consistiu na falta ou no desconhecimento de uma estratégia que direcionasse ao estímulo à participação do cliente, a partir da realidade do próprio indivíduo, na busca de solução para suas dificuldades. Isso implica ressaltar valores e capacidades que os tornassem capazes de participarem de forma independente, aumentando assim a eficácia e a eficiência das ações de educação popular em saúde.

A idéia do descompromisso é passada por meio de alguns discursos da própria população, quando se evidencia que os indivíduos não têm saúde porque não querem, porque não se esforçam ou porque não têm vontade de ter saúde.

Em decorrência das reflexões socializadas deparou-se com os seguintes questionamentos: por que não envolver a família diretamente na prevenção da desnutrição? Por que o enfermeiro não assiste por meio da educação popular em saúde as famílias de crianças desnutridas? De que maneira as famílias estão sendo orientadas (despertadas) na luta pelos seus direitos à saúde, à educação e à cidadania? A prática de educação popular em saúde junto à família de criança desnutrida poderá reverter o quadro de desnutrição?

$\mathrm{Na}$ busca de responder alguns desses questionamentos e considerando a importância da educação popular em saúde junto ao cuidado à criança acometida por desnutrição infantil, foi traçado o objetivo deste estudo: identificar a percepção dos pais acerca das oficinas de educação e saúde e propor ações de educação popular em saúde na assistência à criança desnutrida.

\section{METODOLOGIA}

Trata-se de uma pesquisa-ação que se diferencia como ação educativa composta de avaliação diagnóstica, orientação e devolução da assistência, adequando o envolvimento das pesquisadoras com os participantes para assim alcançar resultados expressivos e que satisfaçam o objeto de estudo. ${ }^{2}$

A pesquisa ocorreu no NAMI, vinculado à UNIFOR, da qual participaram nove famílias (oito mães e um pai), cujos critérios de inclusão foram os seguintes: mães de crianças avaliadas $\mathrm{e}$ 
diagnosticadas como desnutridas durante a consulta de enfermagem, segundo a tabela preconizada pelo National Center for Health Statistics (NCHS); crianças residentes na comunidade Edson Queiroz com consentimento prévio dos responsáveis.

O estudo seguiu as diretrizes e normas regulamentadas pela pesquisa envolvendo seres humanos, com base na Resolução No 196/96 do Conselho Nacional de Saúde, ${ }^{3}$ tendo sido aprovado pelo Comitê de Ética da UNIFOR, parecer No 529/2004. Ressalta-se que os sujeitos do estudo assinaram o Termo de Consentimento Livre e Esclarecido.

A coleta de dados foi realizada no período de março a agosto de 2005, mediante um levantamento nos registros diários dos profissionais de saúde que assistiam crianças desnutridas no NAMI, sendo anotadas as classificações nutricionais de cada cliente. Investigaram-se, então, os prontuários nos quais se verificou o histórico das crianças desnutridas selecionadas, correspondendo à faixa etária de seis meses a cinco anos. Em seguida foram realizadas visitas domiciliares, proporcionando interação entre pesquisador e informante. Vale ressaltar que todas as declarações dos entrevistados foram identificadas por uma legenda que mantém o anonimato dos participantes (ex.: E1, E2, ... E9).

Os participantes, durante a visita domiciliar, foram convidados a comparecer ao NAMI para uma consulta de enfermagem. Após a consulta, foi feito um convite às mães para participarem de oficinas educativas, sendo priorizado o enfoque de educação popular em saúde, utilizando-se como instrumento de pesquisa a observação participante. Após as oficinas, foi aplicada uma entrevista semi-estruturada, que é o procedimento mais usual no trabalho de campo. Por meio dela, o pesquisador busca obter informações contidas nas falas dos atores sociais. Portanto, a questão norteadora final que guiou a entrevista foi: quais as contribuições das oficinas educativas para o cuidar de seu filho desnutrido?

As falas foram organizadas de acordo com a técnica de análise temática uma vez que é um método que trabalha com a subjetividade e a diversificação qualitativa, obtendo, assim, maiores resultados quanto aos objetivos do estudo. ${ }^{4}$

\section{APRESENTAÇÃO DOS RESULTADOS}

Os participantes encontravam-se na faixa etária de 20 a 48 anos. No tocante ao grau de instrução, um era analfabeto, quatro alfabetizados, dois possuíam o ensino fundamental incompleto, um concluiu $\mathrm{O}$ ensino fundamental e um concluiu o ensino médio. Verificou-se o predomínio de casos de união consensual (cinco), uma estava casada nos regimentos civil e religioso, uma era viúva, uma separada e uma solteira. Os participantes se encontravam na rede de economia informal, dos quais seis exerciam as profissões de vigia noturno, faxineiras, vendedora ambulante e costureira. Quanto à renda familiar, oscilou em torno de um a dois salários mínimos, em sete das famílias, e de três salários mínimos, em duas famílias.

\section{Oficinas de educação popular em saúde no cenário de crianças desnutridas}

Sabe-se que o modelo biomédico centrado na medicalização norteou as ações de assistência permeando as unidades de saúde pública, conduzida pela maioria dos profissionais de saúde. Assim, a concepção dos profissionais de saúde, desde meados do século XX, é norteada pelo modelo fragmentador, guardando relação com o paradigma de atenção à saúde atual, centrado nas consultas de enfermagem, direcionadas ao tratamento dos agravos com o auxúlio de recursos tecnológicos. ${ }^{5}$

Incluir nessa prática um direcionamento para a promoção e prevenção de saúde por meio das ações de educação popular em saúde tornou-se necessário ao estudo, como ruptura de um padrão centrado na medicalização e na cura.

$\mathrm{Na}$ reconstrução de uma política de saúde, marcada por embates de interesses e lutas, a educação popular foi um instrumento metodológico central, visando uma atenção integral à saúde, com maior controle das pessoas e grupos sobre sua saúde.

O movimento de educação popular trouxe práticas alternativas ao modelo mercantil e biologista dominante, sobretudo a partir da década de 70. Refere ainda que a participação dos profissionais trouxe uma cultura de relação com as classes populares, que contribuiu para romper com a tradição autoritária e normatizadora da prática educativa. ${ }^{6}$

Nesta pesquisa, relevou-se a coletividade e a cidadania, pois se aventurou a proporcionar aos participantes o desvelar de um aprendizado em conjunto e simultâneo, como também o conhecimento de seus direitos perante a sociedade. Deste modo, as diferenças e as singularidades que cada participante trouxe, foram subsídios fundamentais para a assimilação da problemática, criando possibilidades de transformação em suas ações diárias. 
No desenvolvimento de atendimento ambulatorial, por meio de oficinas educativas, o enfermeiro visa a abrir espaço para discussão, reflexão e compreensão das dificuldades encontradas pelas famílias quanto aos cuidados cotidianos, de modo mais complexo e satisfatório. Consideraram-se também os componentes ambientais, físicos, culturais, sociais, econômicos associados às diversidades de cada família, ressaltando que, em todas as oficinas educativas, trabalharam-se exaustivamente os conceitos de promoção da saúde no contexto saúde e doença.

A promoção da saúde traduz-se em expressões próprias da realidade, com perspectiva de relacionar saúde e condições de vida, compartilhando as situações culturais, econômicas, psicológicas, sociais e ambientais que exercem forte impacto no processo saúde-doença.'

Nas primeiras oficinas proporcionaram-se a familiarização e a reflexão sobre a formação do grupo. $\mathrm{Na}$ intenção de fortalecer a busca pela construção de um projeto, o grupo exprimiu sua maneira de organizar-se e conhecer-se ao longo das oficinas, constituindo-se pela demanda individual e pelas relações sociais e de ajuda entre os participantes. Vale ressaltar que se priorizou trabalhar em círculo, em todas as oficinas, com a valorização das falas e escuta atenta.

As práticas educativas devem permitir aos indivíduos-sujeitos sociais, históricos e culturais, a oportunidade de conhecer e reconhecer a obtenção de destreza para a tomada de decisões, na busca de uma melhor qualidade de vida. É dentro dessas concepções de educação, saúde e educação em saúde que emerge o papel do defensor-facilitador para os grupos sociais com os quais interagem e que necessitem de mudanças sociais. Com isso, os indivíduos resgatam a sua cidadania, colaborando para a promoção da saúde. ${ }^{8}$

Durante as apresentações, verificou-se a dificuldade de alguns participantes em demonstrar suas idéias acerca dos assuntos, impedindo que assimilassem a percepção do outro. Cada participante esteve preocupado com sua problemática e dificuldade de se expor diante do outro, demonstrando com isso um incômodo natural vivenciado por todos que se encontravam naqueles primeiros momentos de formação do grupo. Com o desenrolar das demais oficinas, constatou-se uma evolução, identificada através do envolvimento e do amadurecimento. Todos participavam de modo entusiástico com envolvimento no processo para desvelar os enigmas da desnutrição infantil, com a finalidade de que, num futuro próximo, pudessem prevenir seqüelas à saúde de seus filhos e promover a melhoria na qualidade de vida de suas famílias.

A participação de mães com idade de 43 e 48 anos propiciou ao grupo um sentindo de maior coesão para que fossem socializadas as experiências no cuidado para com o filho desnutrido. Houve também a certificação de uma adoção de atitude prática relacionada à vivência do cotidiano, indispensável à problematização de situações/dificuldades, aproximando-as quanto às experiências vivenciadas frente ao quadro da desnutrição infantil.

O relacionamento entre os participantes foi satisfatório, demonstrando o espírito de cordialidade e respeito mútuo. Conseguiu-se formar uma relação de presteza e segurança, já que compartilhavam de experiências em comum. Presenciaram-se cenas de carinho e corporativismo que, por algum motivo, não podiam estar presentes. Os participantes começaram a reconhecer no outro, problemas semelhantes ou quando a pesquisadora os visitava em sua residência e não estavam presentes, eles mesmos se mobilizavam para que todos ficassem informados sobre a presença da pesquisadora na comunidade. Esta comunicação informal também foi constatada quando os participantes do estudo não eram encontrados em sua casa e no dia seguinte procuravam as pesquisadoras no NAMI, referindo ter sido informada sobre a visita da pesquisadora à sua residência. Essa realidade colaborou na formação de um vínculo de amizade durante os encontros mensais.

A maioria dos participantes (cerca de seis) expressou-se mediante comunicação oral, mas registrouse também, a participação por expressões de gestos, facilidade na apreensão de informações e disposição e disponibilidade durante os momentos vivenciados nos diferentes níveis de escolaridade. Percebeu-se, em razão da quantidade de filhos, que os participantes com menor número de filhos, revelavam um maior envolvimento nas atividades do grupo, constatado por meio das manifestações de interesse.

O fator cultural mostrou-se constante no processo das oficinas, pois representou um conjunto de princípios e crenças que nortearam a forma de ser e de viver dos participantes no que se refere ao cuidado do filho desnutrido. Notou-se tal fator por meio do cuidado desenvolvido pelos participantes na prevenção e tratamento dos agravos à saúde dos filhos, ficando caracterizado que dentro da cultura da comunidade as mães valorizavam seus conhecimentos como no depoimento a seguir: as lombrigas crescem e ficam ai vagando 
no corpo. Não pode comer fruta que tenha verme, como a goiaba e o milho, à noite, porque aí é que elas crescem no corpo, de dia pode; eu sei que a folha do mamão verde é muito boa para cortar os vermes; faz um chá de quebra pedra bem forte, sem açucare dar de manhã que é tiro e queda pra tudo que é ruim?(E5).

Ressalta-se que os participantes respaldam-se no saber popular para a terapêutica dos agravos surgidos no dia-a-dia, como o cuidado ambiental e a utilização de remédios caseiros à base de plantas medicinais. A utilização de plantas como forma de cuidado de doenças é comum na população, e na maioria das culturas que se conhece, e esse recurso terapêutico de cura tem efeito, seja simbolicamente ou de modo mensurável, por meio de comprovação. ${ }^{9}$

As culturas são cercadas por tabus e mitos, que são ações realizadas pelos indivíduos daquela cultura com o objetivo de evitar perigos para ele mesmo e para os outros membros, os quais devem ser conhecidos pelos profissionais de saúde. ${ }^{10}$

Os fatores que se relacionam ao estilo e às condições de vida de um indivíduo ou coletividade são causas determinantes da cultura de uma comunidade. Neste grupo de determinantes incluem-se características como costumes, educação, crenças e hábitos de vida.

A cada oficina realizada, percebia-se o anseio dos participantes em aprender mais sobre o cuidado para com o filho desnutrido por meio de troca de experiências no cenário do grupo. Esse interesse foi percebido por meio de demonstrações práticas comprovadas na visita domiciliar. Com a crescente participação dos participantes no andamento das atividades do grupo, cogitou-se o desejo de torná-los agentes multiplicadores dos conhecimentos adquiridos. Percebeu-se que a idéia foi aceita pelos participantes.

Verificou-se que os participantes se encontravam em processo de mudança, confiantes para atuar junto às suas famílias com determinação, significando que se instrumentalizaram como futuros cuidadores dos filhos desnutridos, mediante seus aprendizados, ou mesmo congregando a autonomia de forma totalitária. É importante ressaltar que esses resultados provêm do próprio envolvimento e das constantes interações com o meio social. As oficinas de educação em saúde serviram de suporte, contribuindo para a sua própria mudança, repercutindo na melhoria do cuidado dos filhos, na estrutura familiar, na evolução do crescimento e no desenvolvimento e favorecimento de interações que emergiram na vida social.

\section{Despertando a consciência do cuidado}

O resultado da ação educativa foi identificado na ampliação da consciência, aquisição de habilidades, surgimento de novos interesses e mudança de comportamento. Como resultante da entrevista, surgiu a categoria "consciência do cuidado" que, dentro da cultura da comunidade na qual estão inseridos, os participantes, apesar das noções básicas do cuidado, aludiram o despertar de uma nova consciência, como pode ser evidenciado nos depoimentos a seguir:

[...] vai contribuir para cuidar desse menino que eu estou esperando. Não vou cair nos mesmos erros de deixar com qualquer pessoa cuidar como eu deixei ela? (E3).

Comecei a ver o que en fazia sem me sentir com a minha filha. Poucas coisas que a gente faz e pensa que não tem importância no cuidado dela, aprendi muito... (E2).

Digo que vou me cobrar mais no cuidado de men filho, pois aprendi que o cuidado com ele é que faltou. Tudo está junto quando se deseja dar saúde para nosso filho (E4).

A ciência das potencialidades e entraves perante a complexidade do cuidado para o desenvolvimento de uma consciência crítica, capaz de superar tais fronteiras, tornou-se relevante. Precisa-se superar os limites e simultaneamente saber-se que não se é onipotente e infalível. É preciso, a cada dia, a cada nova experiência, tentar construir a própria identidade sobre a missão que é cuidar da vida dos seres humanos.

O ser humano necessita de cuidados em sua totalidade, exercendo, assim, uma ação preferencial em relação a sua consciência crítica nas dimensões física, psíquica, social e espiritual. Deixando-se tocar pelo sentimento humano, torna-se um radar de alta complexidade, humaniza-se no processo e tem a chance e o privilégio de crescer em sabedoria, com a valorização e descoberta de que a vida não é um bem a ser privatizado, mas um dom a ser vivido e partilhado. ${ }^{11}$

Deste modo, os profissionais de saúde poderão transformar não só a prática do cuidado, mas também ampliar a consciência da população sobre os determinantes da saúde, as relações com o meio ambiente e o direito à saúde como meios para a promoção da qualidade de vida.

A gente não sabe de muita coisa, mas quando percebe na prática, é que se vê o que a gente realmente sabe e até pode mudar os pensamentos, ficar mais entendido (E8).

Como um dos componentes desta mudança, a educação em saúde constitui-se um forte marco em 
nossas práticas sociais e institucionais neste campo. Educar em saúde é o procedimento pelo qual o indivíduo é habilitado, harmonizando seu auto-conhecimento da realidade, para a identificação das forças que interagem em seu ambiente de vida, cultura e participação na busca conjunta de alternativas de transformação das suas condições de vida. ${ }^{12}$

A prática de aprendizagem permanente e gradativa, com base nas experiências de cada um, em que as mudanças ocorrem a partir das necessidades sentidas, com uma comunicação aberta de respeito e valorização das pessoas envolvidas traduz, sem dúvida, um processo democrático de se auto-cuidar.

A senhora sempre escutava e dava valor às besteiras que a gente falava de cuidar e como a gente tinha conhecimento, pois a gente ia aprendendo umas com as outras... A gente trocou as figuras... (E5).

Depois en vi que a senhora queria era que a gente falasse da nossa vida para ajudar umas às outras e melhorar nossa vida, [...] ensinar e aprender como cuidar de nossos filhos (E9).

Em sentido mais amplo, destaca-se que a missão da educação é fortalecer as condições de possibilidade da emergência de uma sociedade-mundo composta por cidadãos protagonistas, conscientes e criticamente comprometidos com a construção de uma civilização planetária. Tudo isso leva a crer que esse homem, sujeito e autônomo, se forma no processo de educação libertadora. ${ }^{13}$

É necessária, portanto, uma prática educativa em saúde que considere as necessidades reais das pessoas e populações, favorecendo a sua autonomia, liberdade e participação na prevenção, promoção e restabelecimento de sua qualidade de vida. $\mathrm{O}$ protagonismo e a responsabilização desses sujeitos pela vida, compreendem a sua inserção sociopolítica e humanitária, numa relação ética consigo mesmo e com o outro. Este seria o papel fundamental da educação em saúde, articulando diferentes conhecimentos no contexto das políticas de saúde, sociais, econômicas e educacionais.

Tradicionalmente, a educação em saúde tem sido uma ferramenta na qual predomina como saber dominante a responsabilização das pessoas pela diminuição dos agravos à saúde. A educação popular pode ser utilizada como instrumento auxiliar na inclusão de novas práticas por profissionais e serviços de saúde. É notório que, cada vez mais, se busque formas de atender às necessidades dos usuários frente ao acolhimento no atendimento, assim como redefinir o pensar e o fazer na prática educativa em saúde, em função da relevância assumida pelas experiências de promoção da saúde.

Passa-se a criar formas inovadoras no processo de aprendizagem entre um número significativo de profissionais de saúde que, munindo-se de uma metodologia de ação pedagógica na relação de serviços de saúde/população, cujo objetivo fundamental é a colaboração no esforço das classes populares pela conquista dos seus direitos e enfrentamento de seus problemas de saúde. Essas práticas compreendem relações entre sujeitos sociais, ocorrem em diferentes espaços, portam diferentes saberes, e são práticas dialógicas, estratégicas, apresentando-se de maneira formal ou informal, sendo desenvolvidas em espaços públicos ou privados. A sua avaliação consiste em julgar se o esforço empreendido foi alcançado, como foi realizado e quais foram os beneficiados com tais ações. ${ }^{14-15}$ Isto pode ser evidenciado no depoimento: nós aqui não temos muita condição, mas a senhora mostrou que tem que fazer com o que possui e querendo a gente consegue mudar. Eu quero dar o melhor para eles (E6).

Portanto, constatou-se que os participantes se encontravam em completo processo de mudança, acreditando na liberdade para agir, na sua autonomia, com consciência e determinação, o que denota que eles se instrumentalizaram como futuros cuidadores dos filhos por meio de suas práticas, ou mesmo incorporando a pedagogia da autonomia de forma horizontalizada.

Nesse contexto, é necessário chamar a atenção para o fato de que não somente a informação por si só resolverá o problema da desnutrição infantil, uma vez que existem famílias nas quais a desnutrição se deve a fatores transitórios em processo de superação e crises familiares profundas que inviabilizavam o cuidado global das crianças. Assim, o combate à desnutrição depende também de ações muito mais amplas do que os conselhos de normas higiênicas e alimentares e da entrega mensal de alguns pacotes de alimento.

\section{CONCLUSÃO}

A pesquisa retratou a síntese do caminho que se trilhou na construção do conhecimento concernente à educação popular em saúde no cuidado da criança desnutrida. Refletindo sobre o princípio deste estudo, que se traduz na vontade de realizá-lo associada ao objeto estudado e ao planejamento dessa trajetória, reafirma-se com veemência a motivação profissional. 
Após a elucidação dos dados, constatamos que recai sobre os profissionais de saúde a responsabilidade de ser instrumento de fortalecimento dos pais cuidadores dos filhos, reforçando que a educação em saúde tem importância fundamental no desenvolvimento de informações e práticas educativas, que quando em respeito a cada cultura específica pode contribuir sobremaneira para transformar a realidade.

É preciso fazer uso, com mais freqüência, de atividades educativas dentro da metodologia da educação popular, de forma que estas sejam expandidas sistematicamente nos serviços de saúde. A complexidade das práticas educativas, atrelada à necessidade de serem apoiadas por instâncias institucionais, torna necessário que se possibilitem o preparo e as condições prévias ao seu desenvolvimento. Para tanto, o uso de profissionais qualificados com cargas horárias de trabalho significativas dedicadas às mesmas é fundamental.

Constatou-se por meio das oficinas educativas que os pais/participantes se encontravam em processo de mudança, inspirando segurança para agir junto às famílias com poder de resolutividade, significando que se instrumentalizaram como futuros cuidadores dos filhos desnutridos, mediante seus aprendizados, ou mesmo congregando a autonomia de forma totalitária. É importante ressaltar que esses resultados provêm do próprio envolvimento e das constantes interações com o meio social. Assim, as oficinas de educação em saúde foram relevantes no sentido de contribuir com mudanças para as famílias, repercutindo na melhoria do cuidado dos filhos, na estrutura familiar, na evolução do crescimento e no desenvolvimento e favorecimento de interações que emergiram na vida social.

Como resultado final foi possível perceber o despertar de uma consciência do cuidado para com o filho desnutrido revelado pelos pais, evidenciando com isso o contexto cultural da comunidade e os princípios básicos os quais relevaram a sua importância. Neste contexto, a promoção da saúde pode ser entendida como meio para a conquista dos direitos à cidadania. Conseqüentemente, a educação em saúde deverá fazer parte dessas transformações de forma urgente, visando à conscientização tanto dos profissionais de saúde, no desenvolvimento de informações, quanto dos participantes de crianças desnutridas, colaborando para uma efetiva prevenção e promoção de saúde dessa clientela.
A prática de enfermagem relacionada à educação em saúde e, sobretudo, à educação popular em saúde, tem recebido amplo reconhecimento, embora não tenha ainda produzido os resultados necessários e desejados. Permanece com uma lacuna, como um desafio para o profissional que, apesar de consciente, assiste e colabora com os programas estabelecidos pelos órgãos públicos, porém não consegue atingir melhores resultados devido às barreiras socioeconômicas, políticas e de educação em saúde, que consistem fatores fundamentais para o avanço do conhecimento e da conscientização dos próprios trabalhadores da área.

Sugere-se a intervenção por meio de educação popular em saúde como forma de assistência, vislumbrando a sensibilização e a autonomia, por parte dos atores (profissionais e clientes) aqui envolvidos, acerca do cuidado com a saúde. Assim, o cuidado com a criança desnutrida relaciona-se com o procedimento de capacitação, aquisição de conhecimentos acerca da saúde e de consciência crítica, consistindo em uma ferramenta para mudança social, ligando-se ao processo de libertação e autonomia.

Para tanto, faz-se necessária a utilização de metodologias educativas que possibilitem o confronto de saberes, a apreensão da realidade e os seus questionamentos, buscando identificar as raízes culturais, econômicas e sociais presentes e que ocasionam situações vivenciadas por famílias de crianças desnutridas e, conseqüentemente, a busca de uma transformação. Isso, porém, não se deve limitar ao repasse de informações ou mesmo sugerir o autocuidado frente aos agravos de saúde, mas desvelar conhecimentos, formas de enfrentamento e atitudes diante das políticas de saúde das mesmas.

Faz-se necessária a implantação de ações eficazes que contemplem o empenho dos profissionais de saúde, levando em consideração as interações dos fatores sociais e as diversidades culturais das famílias, pelas quais torna-se possível atingir metas positivas nesta temática. Nesta perspectiva, o estudo sugere a viabilização da educação popular em saúde na construção de alternativas aos grandes desafios que a saúde coletiva vem enfrentando, promovendo, desta forma, mudanças e constituindo novos sujeitos e práticas comprometidas com o rompimento das barreiras sociais, econômicas e políticas, bem como com o desenvolvimento da cidadania. 


\section{REFERÊNCIAS}

1 Stotz EN. Os desafios para o SUS e a educação popular: uma análise baseada na dialética da satisfação das necessidades de saúde [acesso em 2005 maio 13]. Disponível em: http:// educaçãopopularemsaude/2005.html

2 Barbier R. A pesquisa-ação. Brasília (DF): Planos; 2002.

3 Ministério da Saúde (BR). Conselho Nacional de Saúde, Comissão Nacional de Ética em Pesquisa. Resolução No 196 de 10 outubro de 1996: diretrizes e normas regulamentadoras de pesquisa envolvendo seres humanos. Brasília (DF): O Conselho; 1996.

4 Bardin L. Análise de conteúdo. Lisboa (PT): Edições 70; 1977.

5 Melo ECP, Cunha FTS, Tonini T. Políticas de saúde pública. In: Figueredo NMA, organizador. Ensinando a cuidar em saúde pública. São Caetano do Sul (SP): Yends; 2005. p.47-72.

6 Vasconcelos EM. Educação popular e a atenção à saúde da família. 2a ed. São Paulo (SP): Hucitec; 2001.

7 Czeresnia D, Freitas CM, organizadores. Promoção da saúde: conceitos, reflexões, tendências. Rio de Janeiro (RJ): Fundação Oswaldo Cruz; 2003.
8 Valla VV, Stotz EN, organizadores. Participação popular e saúde: teoria e prática. Rio de Janeiro (RJ): Relume Dumará; 1993.

9 Frota MA, Barroso MGT. Desnutrição infantil na família: causas obscuras. Sobral (CE): Ed. Uva; 2003.

10 Bezerra MGA, Cardoso MVLML. Fatores culturais que interferem nas experiências das mulheres durante o trabalho de parto e parto. Rev Latino-am Enfermagem. 2006 Maio-Jun, 14 (3): 414-21.

11 Pessini L, Bertachini L, organizadores. Humanização e cuidados paliativos. São Paulo (SP): Ed. Loyola; 2004.

12 D'el Rey DCH. Paradigmas de educação em saúde. Rio de Janeiro (RJ): Pinel; 1996.

13 Morin E. A cabeça bem-feita: repensar a reforma, reformar o pensamento. 9a ed. Rio de Janeiro (RJ): Bertrand Brasil; 2004.

14 Kreutz I, Gaiva MAM, Azevedo RCS. Determinantes sócio-culturais e históricos das práticas populares de prevenção e cura de doenças de um grupo cultural. Texto Contexto Enferm. 2006 Jan-Mar; 15 (1): 89-97.

15 Pedrosa I. Avaliação das práticas educativas em saúde. In: Vasconcelos EM. A saúde nas palavras e nos gestos: reflexões da rede de educação popular e saúde. São Paulo (SP): Hucitec; 2001. 